\title{
SCIDiC
}

\author{
International Journal of Dentistry and Oral Science (IJDOS) \\ ISSN: 2377-8075
}

\section{Comparison Of Manual Toothbrushes With Different Bristle Designs On Gingival Health}

Research Article

\begin{abstract}
N. Padma Priya ${ }^{1}$, Arvina Rajasekar ${ }^{2 *}$
${ }^{1}$ Graduate, Saveetha Dental College and Hospitals, Saveetha Institute of Medical and Technical Sciences (SIMATS), Saveetha University, Chennai- 77, India.

${ }^{2}$ Senior Lecturer, Department of Periodontics, Saveetha Dental College and Hospitals, Saveetha Institute of Medical and Technical Sciences [SIMATS], Saveetha University, Chennai- 77, India.
\end{abstract}

\section{Abstract}

Background: Dental caries and periodontal diseases are among common human illnesses. It is found that the main etiology of periodontal diseases such as gingivitis and periodontitis is the interaction between human immune system and bacteria of dental plaque. Tooth brushing is utilised as the most widely accepted technique for plaque elimination.

Aim: The aim of this study was to compare the effects of three types of manual toothbrushes with different bristle designs including Colgate Cibaca Flat, Colgate Criss Cross and Colgate Slim Soft on gingivitis.

Methodology: The present double blinded, parallel designed, randomized clinical trial was carried out among 72 gingivitis patients in the Department of Periodontics, Saveetha Dental College and Hospitals, Chennai, India. Participants were assigned to three groups: 12 participants in each group [Group A (Colgate Flat), Group B (Colgate Criss Cross) and Group C (Colgate Slim Soft)]. Complete ultrasonic scaling was done for all the participants and subjects were asked not to use any oral hygiene aids and recalled after three days and the gingival index were noted (baseline). Then subjects were provided with respective brushes and instructed to use them for 1 month. Again, gingival index were noted after 1 month. The data was analyzed using Statistical Package for Social Sciences (SPSS Software, Version 23.0). One-way ANOVA was used to compare the mean values of gingival index between the groups. Also, student's paired t-test was used to compare the mean values of gingival index within the groups.

Results: In group 1, the mean gingival index at baseline was $2.671 \pm 0.48$ and after a month the value was reduced to 1.88 \pm 0.44 . In group 2 , the gingival index reduced from $2.63 \pm 0.49$ to $1.29 \pm 0.46$. In group 3 , the mean gingival index at baseline was $2.63 \pm 0.49$ and after a month the value was reduced to $2.00 \pm 0.51$. There was reduction in gingival scores between the three toothbrushes after a month. Also, the difference in gingival index between colgate criss cross and slimsoft was found to be statistically significant $(\mathrm{p}<0.05)$.

Conclusion: The present study suggests that all the three types of toothbrushes were effective in reduction of plaque and gingivitis. However, significant reduction in gingival index score was observed in Colgate slim soft and Colgate criss cross as compared with Colgate flat toothbrush.

Keywords: Dental Plaque; Gingivitis; Innovative; Periodontitis; Toothbrush.

\section{Introduction}

Periodontal diseases which include gingivitis and periodontitis are the most common diseases in the oral cavity. Inflammation of gingiva without the loss of supporting structures of the teeth is called gingivitis. If it is left untreated, it leads to increase in pocket depth, clinical attachment loss, gingival recession, bone loss, fur- cation involvement, pathologic migration and tooth mobility [16]. So it is important to treat gingivitis in its earliest stage itself.

Even though the initiation and progression of periodontal disease is influenced by variety of factors like age, gender, systemic diseases, genetic factors, medication, the bacterial plaque is the primary etiology [7-14]. There are several ways to remove bacte-

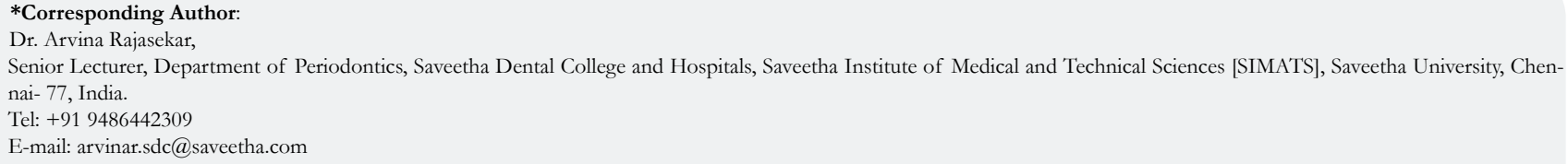

Citation: N. Padma Priva, Arvina Rajasekar. Comparison Of Manual Toothbrushes With Different Bristle Designs On Gingival Health. Int J Dentistry Oral Sci. 2021;8(9):4583-4587. doi: http://dx.doi.org/10.19070/2377-8075-21000933

Copyright: Dr. Arvina Rajasekar ${ }^{\circ} 2021$. This is an open-access article distributed under the terms of the Creative Commons Attribution License, which permits unrestricted use, distribution and reproduction in any medium, provided the original author and source are credited. 
rial plaque including chemical methods and mechanical methods. However, there are so many chemical agents available in the market like chlorhexidine, essential oils, triclosan, herbal mouth rinses; mechanical methods are always considered as the gold standard to remove bacterial plaque [15]

Tooth brushing is utilized as the most widely accepted technique for plaque elimination among adults and children. There are numerous factors that affect sufficiency of tooth brushing including frequency, duration, dexterity, toothbrush design and technique. Be that as it may, controlling plaque aggregation for forestalling gum disease and additionally periodontitis and rots adequately is impacted by various individual and material based elements [16]. These principle elements can be summed up as the plan of the toothbrush, the expertise of the individual utilizing the brush, and toothbrushing recurrence and length of utilization. The last two elements address individual toothbrushing conduct and are influenced by learning experience, inspiration and manual limit and can obviously be improved with acceptable co-activity set up among dental specialists and patients [17].

Notwithstanding, the primary factor addresses innovation improvement and is influenced by the physical and mechanical properties of the toothbrush bristles and the shape, size and morphometry of the tooth brush heads and handles [18].

Besides, it was notable that the vast majority utilize a straightforward flat tooth brushing activity and brush their teeth for the span uniquely more limited than ideal time [19]. Producers of toothbrushes focus on developments in the brush head plan that will assist with making up for non ideal toothbrushing method and time [20]. The more fundamental plans incorporate toothbrushes with standard (flat) bristles and further developed models with angulated (Criss Cross) bristles uncommonly targeting assisting with eliminating plaque from teeth and along the gum line [19]. The high level toothbrushes can possibly eliminate more prominent measures of plaque, particularly from the gum lines and approximate surfaces than ordinary tooth brushes fusing straight bristles [21]. There have been conflicting results on which design is more capable of effective plaque control.

Our team has extensive knowledge and research experience that translate into high quality publication [22-41]. To the best of our knowledge, there are minimal studies assessing the efficacy of manual toothbrushes with different bristle designs on plaque removal [42]. In this context, the aim of this study was to compare the effects of three types of manual toothbrushes with different bristle designs including Colgate Cibaca Flat, Colgate Criss Cross and Colgate Slim Soft on gingivitis.

\section{Materials and Methods}

\section{Study Population:}

The present double blinded, parallel designed, randomized clinical trial was carried out in the Department of Periodontics, Saveetha Dental College and Hospitals, Chennai, India. A total of 144 patients with gingivitis were enrolled. The ethical clearance was obtained from the Institutional Ethical Committee and a written informed consent was obtained from all the study participants.

\section{Inclusion Criteria:}

Participants within the age group of 20-25 were systematically healthy, presence of at least 20 teeth, probing depth of $1-3 \mathrm{~mm}$, presence of bleeding on probing (BOP) in at least 30 percent of sites were included in the study.

\section{Exclusion Criteria:}

Participants who were under orthodontic treatment and used other electric brushes were excluded, participants under long term medications, systemically compromised patients were excluded from the study.

\section{Test group:}

Group A: Colgate flat brush

Group B: Colgate Criss Cross brush

Group C: Colgate slim Soft brush

\section{Study Design:}

A pilot study was conducted using similar brushes to check the feasibility of the study. The prevalence of gingivitis was $80 \%$ in the pilot study. Considering the dropouts, the sample size was inflated by $20 \%$, hence the sample size was 144 with 48 participants in each group [Group A (Flat brush), Group B ( Criss Cross) and Group C (Slim Soft)]. Participants were assigned to the groups by a person not involved in the study. All the subjects were provided with their assigned tooth brushes and were divided into Group A, Group B and Group C randomly using a simple lottery method with 48 participants in each group. The examiner and the participants were also blinded with regard to the tooth brushes allocated to them thereby ensuring a double-blinded study. Complete ultrasonic scaling was done for all the participants and subjects were asked not to use any oral hygiene aids and recalled after three days and gingival index was recorded (baseline). Then subjects were provided with respective brushes and instructed them to use modified bass technique for a period of 1 month. The gingival index was noted again after 1 month.

\section{Clinical parameters:}

- Silness and Loe Gingival index (1963) (GI)

GI was recorded at baseline (T1) and after 1 month (T2).

\section{Statistical Analysis:}

The data was analyzed using Statistical Package for Social Sciences (SPSS Software, Version 23.0). Descriptive and inferential statistics were done for data summarization and presentation. One-way ANOVA was used to compare the mean values of gingival index between the groups. Also, student's paired t-test was used to compare the mean values of gingival index within the groups.

\section{Results}

A total of 72 study participants were enrolled in this study and were divided into three groups each of 12 participants. Group AColgate Flat, group B- Colgate Criss Cross and group C- Colgate Slim Soft. 
Table 1. Comparison of mean gingival index score within the study groups using paired t-test.

\begin{tabular}{|c|c|c|}
\hline Mean+SD & Before treatment & After treatment \\
\hline Brush A & $2.671 \pm 0.48$ & $1.88 \pm 0.44$ \\
\hline Brush B & $2.63 \pm 0.49$ & $1.29 \pm 0.46$ \\
\hline Brush C & $2.63 \pm 0.49$ & $2.00 \pm 0.51$ \\
\hline
\end{tabular}

Table 2. Comparison of mean gingival index score between the study groups using ANOVA test.

\begin{tabular}{|c|c|c|c|c|c|}
\hline & Groups (I) & Groups (J) & Mean difference & Std. Error & Significant \\
\cline { 2 - 6 } & \multirow{4}{*}{ Brush A } & Brush B & 0.315 & 0.140 & 0.066 \\
\cline { 3 - 6 } & & Brush C & -0.07 & 0.137 & 0.866 \\
\cline { 2 - 6 } & \multirow{3}{*}{ Brush B } & BrushA & -0.315 & 0.140 & 0.066 \\
\cline { 3 - 6 } & & Brush C & -0.385 & 0.138 & $0.017^{*}$ \\
\cline { 3 - 6 } & \multirow{2}{*}{ Brush C } & Brush A & 0.07 & 0.137 & 0.866 \\
\cline { 3 - 6 } & & Brush B & 0.385 & 0.138 & $0.017^{*}$ \\
\hline
\end{tabular}

$* \mathrm{p}<0.05$

Figure 1. The bar graph depicts the association between the types of toothbrush versus the gingival index scores. The $\mathrm{X}$ axis represents the pre gingival index scores (blue) and post-gingival index scores (green). There was reduction in gingival scores in all the three toothbrushes from baseline. Also, the difference in gingival index between Brush B and Brush $\mathrm{C}$ was found to be statistically significant with the $p$ value of 0.017 (ANOVA test, $p<0.05$ ).

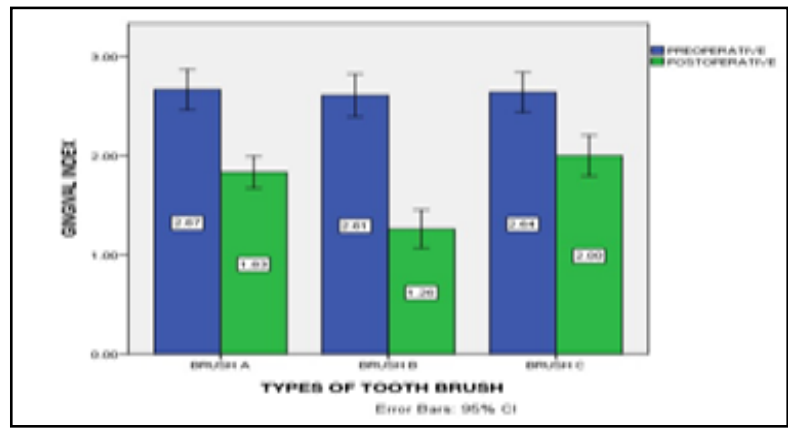

The paired t test was done to compare the mean gingival index within the groups. In group 1, the mean gingival index at baseline was $2.671 \pm 0.48$ and after a month the value was reduced to $1.88 \pm 0.44$. In group 2 , the gingival index reduced from $2.63 \pm 0.49$ to $1.29 \pm 0.46$. In group 3 , the mean gingival index at baseline was $2.63 \pm 0.49$ and after a month the value was reduced to $2.00 \pm 0.51$. (Table 1).

ANOVA test was done to compare the mean gingival index (Table2) between the three groups. There was reduction in gingival scores between the three toothbrushes after a month. Also, the difference in gingival index between colgate criss cross and slimsoft was found to be statistically significant $(p<0.05)$. (Figure 1).

\section{Discussion}

The present study was done to compare the manual toothbrushes with different bristle designs on gingival health.

In the present study, all the three types of toothbrushes resulted in significant reduction in gingival index scores. A study conducted by Sharma et al. have reported that criss-cross bristles angled in opposing directions promote plaque removal from hard-to-reach areas and have advantages over the straight bristle configuration.
The researchers concluded that advances in toothbrush design can present greater plaque removal outcomes [19]. In another study, it was observed that befuddle bristles were effective in plaque removal when compared with straight bristle design [43].

In a recent clinical study, the influence of three manual toothbrushes on dental plaque and gingival inflammation was investigated. The Plaque index and Gingival index scores were statistically significantly lower in subjects using the tapered and cross angled soft bristle design toothbrushes than those using the American Dental Association (ADA) standard toothbrushes after 30 days [19]. The result obtained in present study is in accordance with the previous studies as significant reduction in gingival index scores was observed in criss cross type of toothbrush.

Similarly, Verma SK et al.,[44] compared the degree of plaque removal obtained with the use of two commercially available toothbrushes with round ended and thinner ended bristles and it was found out that both the brushes showed similar decrease in plaque scores. Naik SP et al.,[45] compared the effectiveness of different bristles designs of toothbrushes and periodontal status among fixed orthodontic patients. In that study, toothbrushes with zig zag bristles, crisscross bristles and flat bristles were compared. The results revealed that all the three designs of tooth brushes were effective in removing plaque in patients with fixed 
orthodontic appliances. But toothbrushes with crisscross bristle design showed the highest mean plaque reduction. The results of the present study are in accordance with the previous studies.

\section{Conclusion}

Within the limitations, the present study suggests that all the three types of toothbrushes were effective in reduction of plaque and gingivitis. However, significant reduction in gingival index score was observed in Colgate slim soft and Colgate criss cross as compared with Colgate flat toothbrush.

\section{Acknowledgement}

The authors would like to acknowledge the help and support rendered by the Department of Periodontics, Saveetha Dental College and Hospitals, Saveetha Institute of Medical and Technical Sciences, Saveetha University, Chennai.

\section{Funding}

The present study is funded by

- Saveetha Institute of Medical and Technical Sciences

- Saveetha Dental College and Hospitals

- Saveetha University

- Lakshmi farm seeds Private Ltd, Virudhunagar.

\section{References}

[1]. Rajeshwaran N, Rajasekar A, Kaarthikeyan G. Prevalence of Pathologic Migration in Patients with Periodontitis: A Retrospective Analysis. J. Complement. Med. Res.2020;11(4):172-8.

[2]. DAVE PH, RAMAKRISHNAN M. Association of Tooth Loss in Chronic Periodontitis Patients with And Without Mellitus. J. contemp. issues bus. gov. $2021 \mathrm{Feb}$ 8;27(2):313-23.

[3]. Rajeshwaran N, Rajasekar A. Prevalence of Angular Bone Defects in Chronic Periodontitis Patients with and without Systemic Diseases. Indian J. Forensic Med. Toxicol. 2020 Oct 1;14(4).

[4]. KARTHIKEYAN MURTHYKUMAR DR, KAARTHIKEYAN DG. Prevalence of Tooth Loss Among Chronic Periodontitis Patients-A Retrospective Study.Int. J. Pharm. Res. 2020 Jul;12(2).

[5]. Murthykumar K, Rajasekar A, Kaarthikeyan G. Assessment of various treatment modalities for isolated gingival recession defect- A retrospective study. Int. j. res. pharm. sci. 2020;11: 3-7.

[6]. Sabarathinam J, Rajasekar A, Madhulaxmi M. Prevalence of Furcation Involvement Among Patients with Periodontitis: A Cross Sectional Study. Int. J. Res. Pharm. Sci. 2020;11: 1483-7.

[7]. Rajasekar A, Mathew MG. Prevalence of Periodontal Disease among Individuals between 18-30 Years of Age: A Retrospective Study. Ann Med Health Sci Res. 2021 Jun 30

[8]. B G, Geethika B, Rajasekar A, Chaudary M. Comparison of periodontal status among pregnant and non-pregnant women. Int. j. res. pharm. sci.. 2020;11: 1923-6.

[9]. Rajasekar A, Lecturer S, Department of Periodontics, Saveetha Dental College and Hospitals, Saveetha Institute of Medical and Technical Sciences, Saveetha University, et al. Assessment Of Periodontal Status among Post Menopausal Women: A Retrospective Study. Int. J. Dent. Oral Sci. 2020. p. $1063-6$

[10]. Kandhan TS, Rajasekar A. Prevalence of Periodontal Diseases Among Patients with And Without Systemic Diseases-A Retrospective Study. J. Complement. Med. Res. 2020;11(4):155-62.

[11]. Assessment of periodontal health among patients with diabetes mellitus: a retrospective study. J. contemp. issues bus. gov. 2021;26.

[12]. SHAH P, RAJASEKAR A, CHAUDHARY M. Assessment of Gender Based Difference in Occurrence of Periodontal Diseases: A Retrospective Study. J. contemp. issues bus. gov. $2021 \mathrm{Feb}$ 16;27(2):521-6.

[13]. MOHD AZLAN SUNIL NS, RAJASEKAR A, DURAISAMY R. Evalu- ation of Periodontal Health Adjacent to Class V Restoration. J. contemp. issues bus. gov. $2021 \mathrm{Feb}$ 15;27(2):324-9.

[14]. RAJASEKAR A, CHAUDARY M. Prevalence of Periodontal Diseases Among Individuals Above 45 Years: A Retrospective Study. J. contemp. issues bus. gov. $2021 \mathrm{Feb} 19 ; 27(2): 527-33$.

[15]. Evaluation of Antiplaque and Antigingivitis Effects of A Herbal Mouthwash. Int. J. Pharm. Res. 2021;13.

[16]. Jensen SB, Borglum Jensen S, Loe H, Rindom Schiott C, Theilade E. Experimental gingivitis in man. J Periodontal Res. 1968;3: 284-93.

[17]. Yankell SL, Shi X, Emling RC, Bucker R, Loudin S. Laboratory evaluation of two bi-level toothbrush products for subgingival access and gingival margin cleaning. J Clin Dent. 2000;11(1):20-3.Pubmed PMID: 11460289.

[18]. Von der Fehr FR. Experimental caries in man. Caries Res.. 1970;4:131-48.

[19]. Löe H, Kleinman DV, editors. Dental plaque control measures and oral hygiene practices: proceedings from a state-of-the-science workshop. Irl Press; 1986:332.

[20]. Slot DE, Wiggelinkhuizen L, Rosema NA, Van der Weijden GA. The efficacy of manual toothbrushes following a brushing exercise: a systematic review. Int. J. Dent. Hyg. 2012 Aug;10(3):187-97.

[21]. Ren YF, Cacciato R, Whelehan MT, Ning L, Malmstrom HS. Effects of toothbrushes with tapered and cross angled soft bristle design on dental plaque and gingival inflammation: a randomized and controlled clinical trial. J Dent. 2007 Jul;35(7):614-22.Pubmed PMID: 17544560.

[22]. Ramesh A, Varghese S, Jayakumar ND, Malaiappan S. Comparative estimation of sulfiredoxin levels between chronic periodontitis and healthy patients - A case-control study. J Periodontol. 2018 Oct;89(10):1241-1248.Pubmed PMID: 30044495 .

[23]. Paramasivam A, Priyadharsini JV, Raghunandhakumar S, Elumalai P. A novel COVID-19 and its effects on cardiovascular disease. Hypertens. Res. $2020 \mathrm{Jul} ; 43(7): 729-30$.

[24]. S G, T G, K V, Faleh A A, Sukumaran A, P N S. Development of 3D scaffolds using nanochitosan/silk-fibroin/hyaluronic acid biomaterials for tissue engineering applications. Int J Biol Macromol. 2018 Dec;120(Pt A):876885.Pubmed PMID: 30171951.

[25]. Del Fabbro M, Karanxha L, Panda S, Bucchi C, Doraiswamy JN, Sankari $\mathrm{M}$, et al. Autologous platelet concentrates for treating periodontal infrabony defects. Cochrane Database Syst. Rev. 2018;11.

[26]. Paramasivam A, Vijayashree Priyadharsini J. MitomiRs: new emerging microRNAs in mitochondrial dysfunction and cardiovascular disease. Hypertens Res. 2020 Aug;43(8):851-853.Pubmed PMID: 32152483.

[27]. Jayaseelan VP, Arumugam P. Dissecting the theranostic potential of exosomes in autoimmune disorders. Cell Mol Immunol. 2019 Dec;16(12):935-936. Pubmed PMID: 31619771.

[28]. Vellappally S, Al Kheraif AA, Divakar DD, Basavarajappa S, Anil S, Fouad $\mathrm{H}$. Tooth implant prosthesis using ultra low power and low cost crystalline carbon bio-tooth sensor with hybridized data acquisition algorithm. Comput. Commun. 2019 Dec 15;148:176-84.

[29]. Vellappally S, Al Kheraif AA, Anil S, Assery MK, Kumar KA, Divakar DD. Analyzing Relationship between Patient and Doctor in Public Dental Health using Particle Memetic Multivariable Logistic Regression Analysis Approach (MLRA2). J Med Syst. 2018 Aug 29;42(10):183.Pubmed PMID: 30155746.

[30]. Varghese SS, Ramesh A, Veeraiyan DN. Blended Module-Based Teaching in Biostatistics and Research Methodology: A Retrospective Study with Postgraduate Dental Students. J Dent Educ. 2019 Apr;83(4):445-450.Pubmed PMID: 30745352

[31]. Venkatesan J, Singh SK, Anil S, Kim SK, Shim MS. Preparation, Characterization and Biological Applications of Biosynthesized Silver Nanoparticles with Chitosan-Fucoidan Coating. Molecules. 2018 Jun 12;23(6):1429.Pubmed PMID: 29895803.

[32]. Alsubait SA, Al Ajlan R, Mitwalli H, Aburaisi N, Mahmood A, Muthurangan $\mathrm{M}$, et al. Cytotoxicity of different concentrations of three root canal sealers on human mesenchymal stem cells. Biomolecules. 2018 Sep;8(3):68.

[33]. Venkatesan J, Rekha PD, Anil S, Bhatnagar I, Sudha PN, Dechsakulwatana C, et al. Hydroxyapatite from cuttlefish bone: isolation, characterizations, and applications. Biotechnol. Bioprocess Eng. 2018 Aug;23(4):383-93.

[34]. Vellappally S, Al Kheraif AA, Anil S, Wahba AA. IoT medical tooth mounted sensor for monitoring teeth and food level using bacterial optimization along with adaptive deep learning neural network. Measurement. 2019 Mar 1;135:672-7.

[35]. PradeepKumar AR, Shemesh H, Nivedhitha MS, Hashir MMJ, Arockiam S, Uma Maheswari TN, et al. Diagnosis of Vertical Root Fractures by Conebeam Computed Tomography in Root-filled Teeth with Confirmation by Direct Visualization: A Systematic Review and Meta-Analysis. J Endod. 2021 Aug;47(8):1198-1214.Pubmed PMID: 33984375.

[36]. R H, Ramani P, Tilakaratne WM, Sukumaran G, Ramasubramanian A, Krishnan RP. Critical appraisal of different triggering pathways for the 
pathobiology of pemphigus vulgaris-A review. Oral Dis. 2021 Jun 21.Pubmed PMID: 34152662.

[37]. Ezhilarasan D, Lakshmi T, Subha M, Deepak Nallasamy V, Raghunandhakumar $\mathrm{S}$. The ambiguous role of sirtuins in head and neck squamous cell carcinoma. Oral Dis. 2021 Feb 11.Pubmed PMID: 33570800.

[38]. Sarode SC, Gondivkar S, Sarode GS, Gadbail A, Yuwanati M. Hybrid oral potentially malignant disorder: A neglected fact in oral submucous fibrosis. Oral Oncol. 2021 Oct:121:105390.Pubmed PMID: 34147361.

[39]. Kavarthapu A, Gurumoorthy K. Linking chronic periodontitis and oral cancer: A review. Oral Oncol. 2021 Jun 16:105375.

[40]. Vellappally S, Al-Kheraif AA, Anil S, Basavarajappa S, Hassanein AS. Maintaining patient oral health by using a xeno-genetic spiking neural network. J. Ambient Intell. Humaniz. Comput. 2018 Dec 14:1-9.

[41]. Aldhuwayhi S, Mallineni SK, Sakhamuri S, Thakare AA, Mallineni S, Sajja R, et al. Covid-19 Knowledge and Perceptions Among Dental Specialists: A Cross-Sectional Online Questionnaire Survey. Risk Manag Healthc Policy. 2021 Jul 7;14:2851-2861.Pubmed PMID: 34262372.
[42]. Ccahuana-Vasquez RA, Adam R, Conde E, Grender JM, Cunningham P, Goyal CR, et al. A 5-week randomized clinical evaluation of a novel electric toothbrush head with regular and tapered bristles versus a manual toothbrush for reduction of gingivitis and plaque. Int J Dent Hyg. 2019 May;17(2):153-160.Pubmed PMID: 30375187.

[43]. Strate J, Cugini MA, Warren PR, Qaqish JG, Galustians HJ, Sharma NC. A comparison of the plaque removal efficacy of two power toothbrushes: Oral-b Professional Care Series versus Sonicare Elite. Int Dent J. 2005 Jun;55(3):151-6.Pubmed PMID: 15997965.

[44]. Verma SK, Sharma N, Singh S, Razi MA. Comparison of different tooth brushes on the degree of plaque removal. J Family Med Prim Care. 2020 Feb;9(2):556

[45]. Naik SP, Punathil S, Shetty P, Jayanti I, Jalaluddin M, Avijeeta A. Effectiveness of Different Bristle Designs of Toothbrushes and Periodontal Status among Fixed Orthodontic Patients: A Double-blind Crossover Design. J Contemp Dent Pract. 2018 Feb 1;19(2):150-155.Pubmed PMID: 29422463. 